\title{
"LIDERE COMO JESUS" - LIDERANÇA E AUTOAJUDA NA MÍDIA EVANGÉLICA NOS ESTADOS UNIDOS E NO BRASIL (1980-2010)
}

\author{
Karina Kosicki Bellotti ${ }^{1}$
}

\begin{abstract}
Resumo: O texto versa sobre os livros de liderança baseados na figura de Jesus Cristo e no modelo de liderança servidora, escritos por autores norte-americanos, com tradução para o público brasileiro. Nossa abordagem segue a análise das relações entre religião e mídia, utilizando uma perspectiva histórica do desenvolvimento da literatura de liderança secular e religiosa ao longo do século XX. Fizemos uma revisão histórica e bibliográfica sobre a literatura de liderança e suas relações com determinados valores espirituais, morais e mitológicos da sociedade capitalista ocidental no século XX. Por fim, analisamos quais representações de Jesus Cristo são tomadas neste tipo de literatura, para analisar o modelo de liderança servidora em duas produções - a pioneira "The servant as leader", de Robert K. Greenleaf (1970), e "Lidere como Jesus" (2007), de Ken Blanchard e Phil Hodges. A literatura reforça uma narrativa mitológica advinda da literatura secular de liderança, confortando seus leitores com a possibilidade de exercer uma influência positiva sobre as pessoas a partir de um modelo considerado inquestionável de bondade e retidão, ao mesmo tempo em que prescreve conselhos para atingir a excelência no mundo capitalista.
\end{abstract}

Palavras chave: Literatura de liderança. Liderança Servidora. Religião e Mídia. Protestantismo.

\section{"LEAD LIKE JESUS" - LEADERSHIP AND SELF-HELP IN THE EVANGELICAL MEDIA IN THE UNITED STATES AND IN BRAZIL (1980s-2010s)}

\begin{abstract}
This article is about the books of leadership based on the image of Jesus Christ and on the model of servant leadership, written by North-American authors, translated into Portuguese. The approach follows the analysis of the relations between religion and media, using a historical perspective of the development of the secular and religious literature of leadership throughout the twentieth century. It was made a historical and bibliographical revision of the leadership literature and its relations with certain spiritual, moral and mythological values of the Western capitalist society in the 20th century. At the end, it was analyzed which representations of Jesus Christ were taken in such literature, in order to study the model of servant leadership in two books: the pioneer "The servant as leader", by Robert K. Greenleaf (1970), and "Lead like Jesus" (2007), by Ken Blanchard and Phil Hodges. Such literature reinforces a mythological narrative taken from the secular leadership literature, comforting its readers with the possibility of exerting positive influence on people by a supposedly unquestionable model of goodness and righteousness, and at the same time, it prescribes counseling to achieve excellence in the capitalist world.
\end{abstract}

Keywords: Leadership literature. Servant Leadership. Religion and Media. Protestantism.

\footnotetext{
${ }^{1}$ Docente dos Cursos de Graduação e Pós-Graduação do Departamento de História da Universidade Federal do Paraná (UFPR).

E-mail: karinakbellotti@gmail.com
}

Fronteiras: Revista de História | Dourados, MS | v. 19 | n. 34 | p. 207 - 233 | Jul. / Dez. 2017 


\section{"LIDERE COMO JESÚS" - LIDERAZGO Y AUTOAYUDA EN LA MEDIA EVANGÉLICA EN LOS ESTADOS UNIDOS Y EN BRASIL (1980-2010)}

Resumen: El texto versa sobre los libros de liderazgo basados en la figura de Jesucristo y en el modelo de liderazgo de la servidumbre, escritos por autores norteamericanos, con traducción al público brasileño. Nuestro enfoque sigue el análisis de las relaciones entre religión y medios de comunicación, utilizando una perspectiva histórica del desarrollo de la literatura de liderazgo secular y religiosa a lo largo del siglo XX. Hemos hecho una revisión histórica y bibliográfica sobre la literatura de liderazgo y sus relaciones con determinados valores espirituales, morales y mitológicos de la sociedad capitalista occidental en el siglo XX. Por último, analizamos qué representaciones de Jesucristo se toman en este tipo de literatura, para analizar el modelo de liderazgo que sirve en dos producciones - la pionera "The servant las líder", de Robert K. Greenleaf (1970), y "Lidere como Jesús "(2007), de Ken Blanchard y Phil Hodges. La literatura refuerza una narrativa mitológica proveniente de la literatura secular de liderazgo, confortando a sus lectores con la posibilidad de ejercer una influencia positiva sobre las personas a partir de un modelo considerado incuestionable de bondad y rectitud, al mismo tiempo que prescribe consejos para alcanzar la excelencia en el mundo capitalista.

Palabras clave: Literatura de liderazgo. Liderazgo Servidora. Religión y Medios de comunicación. Protestantismo.

\section{INTRODUÇÃO}

Nos últimos anos, quem deseja ser líder encontra aconselhamento em diversos meios: cursos, consultorias, eventos e livros sobre liderança, seguindo uma enorme variedade de exemplos seculares e religiosos. O crescimento da visibilidade deste tema levou à realização da pesquisa que embasa este texto, que enfatiza um tipo específico de aconselhamento - os livros de liderança baseados na figura de Jesus Cristo e o modelo de liderança servidora, escritos por autores norte-americanos, com tradução para o público brasileiro. Nossa abordagem segue a análise das relações entre religião e mídia, utilizando uma perspectiva histórica do desenvolvimento da literatura de liderança secular e religiosa ao longo do século XX.

Seguimos as seguintes indagações: como compreender este aconselhamento? Desde quando ele existe? Como se relaciona com a produção midiática de liderança, religiosa e secular? Quando chega ao Brasil e por meio de quais agentes? E como tem circulado em nosso país? Além disso, nossa reflexão procura investigar os sentidos que esta literatura de aconselhamento tem desenvolvido, visando seu público alvo - aliás, que público-alvo é este? 
A revisão da produção bibliográfica sobre este assunto não nos revela pesquisas sobre este tema específico dentro do campo historiográfico nem no Brasil, nem nos Estados Unidos. Encontra-se uma grande quantidade de pesquisas na área de liderança - os estudos de liderança, conduzidos majoritariamente nas áreas de administração de empresas e psicologia social, em funcionamento desde os anos 1930 nos Estados Unidos. Ademais, existem periódicos e publicações norte-americanos voltados para liderança cristã, com ênfase na formação pastoral e na administração de igrejas (em sua maioria, publicações evangélicas). No Brasil, encontramos tanto o material brasileiro e norte-americano sobre liderança em periódicos e livros nas áreas de administração e psicologia, quanto material sobre liderança religiosa na lista de algumas editoras evangélicas e seculares, dividindo-se nas categorias de liderança voltada para pastores e líderes de células, e liderança voltada para um público mais amplo. É esta última categoria que será analisada aqui.

Por que escolher livros de liderança que tomam Jesus Cristo como modelo de líder e até de executivo? A categoria de "livros populares", como definiu Erin A. Smith (2015), revela-nos muito sobre as expectativas e as formas de compreensão de determinados temas num dado período histórico. Para além das análises sobre gosto ou formação intelectual, tais $\operatorname{livros}^{2}$ nos mostram as relações que seus autores estabelecem com o seu público imaginado, oferecendo prognósticos e soluções para os problemas da sociedade, divulgando esperanças ou catástrofes, consolando seus interlocutores, que não necessariamente pertencem a uma religião. $\mathrm{O}$ aspecto religioso tem se integrado recentemente a esta indústria da liderança, após o aumento da popularidade dos livros de liderança seculares a partir dos anos 1980 nos Estados Unidos, e anos 1990 no Brasil. E no caso dos livros baseados em figuras religiosas, Jesus Cristo é novamente superstar.

Nesta reflexão, apresentaremos considerações sobre a abordagem acerca de religião e mídia, seguindo para a revisão histórica e bibliográfica sobre a literatura de liderança e suas relações com determinados valores espirituais, morais e mitológicos da sociedade capitalista

\footnotetext{
2 Tais livros nos levam a outros instrumentos de promoção da liderança com bases religiosas: as empresas de consultoria, tal como a Envisionar, fundada por Josué Campanhã, presidente da Sepal (Serviço de Evangelização para a América Latina); os institutos de coaching cristão, existentes no Brasil (Instituto Cristão de Coaching) e nos Estados Unidos (Professional Christian Coaching, Christian Coach Institute; International Christian Coaching Association, dentre outros); seminários de liderança de alcance global (Global Summit Leadership, supracitado). Ainda que não sejam o objeto central da pesquisa, não podemos negligenciar sua existência, atrelada a uma série de publicações que alimentam o interesse em melhorar as capacidades e habilidades de liderança de qualquer pessoa.
} 
ocidental no século XX. Por fim, analisaremos quais representações de Jesus Cristo são tomadas neste tipo de literatura, para analisar o modelo de liderança servidora em duas produções - a pioneira "The servant as leader", de Robert K. Greenleaf (1970), e "Lidere como Jesus" (2007), de Ken Blanchard e Phil Hodges.

\section{ABORDAGEM SOBRE RELIGIÃO, MÍDIA E CULTURA}

Para compreender os conceitos religiosos de liderança trazidos ao Brasil, levantamos a produção dos estudos e dos livros populares sobre liderança nos Estados Unidos. A pergunta que todo historiador deve fazer, em especial quando trabalha com uma suposta história do tempo presente - tendo em vista que os livros escolhidos como fontes primárias foram publicados entre os anos 1980 e 2010-, é: quão novo é o fenômeno estudado?

Para responder a esta questão, destacamos a contribuição dos estudos de mídia e religião (HOOVER, 2006) para compreender este material. Tal campo, iniciado nos anos 1980 nos Estados Unidos, e com plena difusão pelo mundo a partir dos anos 1990, enfatiza a midiatização da religião como fator de transformação de identidades, alteridades e subjetividades religiosas, dentro e fora da religião organizada. O mercado editorial é um bom exemplo da atuação da midiatização, em especial desde o século XIX nos Estados Unidos, quando a produção em massa de publicações contribuiu para a reafirmação e para o questionamento de identidades institucionais, e para a proposta de outras formas de viver a espiritualidade (BOYER \& COHEN, 2008; SMITH, 2015), incentivando a autonomia religiosa dos indivíduos - ao menos daqueles com acesso a este tipo de material.

Os livros que analisamos fazem parte de uma longa tradição de livros populares de aconselhamento, também denominados de "auto-ajuda" ou "inspiracionais" (ANKER, 1999), constituem um gênero próprio: são manuais de "como fazer", com um passo a passo para os leitores atingirem os objetivos propostos na publicação. Alguns livros trazem recursos pedagógicos, com questionários e espaços para reflexão individual, para que os leitores desenvolvam os conhecimentos trazidos pelos autores. Não raro são livros com capítulos curtos, repletos de histórias que ilustram os princípios ensinados, para mostrar como eles dão certo. É pelo formato que diferenciamos os livros acadêmicos seculares sobre liderança dos livros mais 
populares, seculares e religiosos, pois, no que se refere ao conteúdo, há uma grande referência a teorias e filosofias da liderança produzidas em diferentes contextos históricos.

Os livros religiosos de liderança são veículo para expressão de ideias de seus autores, e à medida que demonstram boa vendagem, geram outros livros, além de palestras, e até serviços de consultoria e ministérios próprios. Nem sempre seus autores são lideranças religiosas, e nenhum dos livros consultados até o momento faz proselitismo de uma igreja ou instituição religiosa. $\mathrm{O}$ fato de não possuírem uma filiação religiosa explícita - ainda que muitos autores se declarem cristãos - permite que os livros figurem sem muitas restrições entre diferentes círculos religiosos e seculares. No presente artigo, não trabalharemos com a recepção dos livros - mas pelos formatos e pelos conteúdos dos livros analisados é possível lançar reflexões sobre os sentidos destas mensagens, e entender porque num contexto mais recente - e, não, em outro - estes livros ganham maior projeção.

\section{HISTÓRICO DA LITERATURA DE LIDERANÇA NOS ESTADOS UNIDOS}

Inserimos a datação da literatura de liderança com base em figuras religiosas no levantamento das vertentes de produção mais ampla sobre liderança. As apropriações do discurso religioso por este campo são recentes, datando dos anos 1980, com crescimento nos anos 1990 e 2000. A literatura secular de liderança³ ${ }^{3}$, por sua vez, segundo Joseph Rost (1991), é um fenômeno da virada do século XIX para o XX, que só cresce em popularidade e no meio acadêmico a partir dos anos 1980. Rost não se refere a livros religiosos, mas suas análises apontam para as dimensões mitológicas da literatura de liderança.

\footnotetext{
${ }^{3}$ O termo inglês "leadership" (liderança) tem registro apenas a partir do século XIX no vocábulo anglo-saxão - no Webster's An American Dictionary of English Language, em 1828 (liderança é o estado ou condição de um líder ROST, 1991, pp. 39-40), tendo maior número de registros em dicionários a partir da virada do século XIX para o XX, associando-se a duas abordagens que conceituam liderança, a das ciências da administração e da psicologia social. Assim, enquanto os termos "leader" (líder), "to lead" (liderar) e "leading" (liderança) possuíam amplo uso desde o século XIII (podendo ser encontrado tanto no latim - ducere - quanto nas línguas anglo-saxãs por volta do século VIII), "leadership" define-se como a habilidade de exercer liderança; a capacidade de exercer liderança; a atribuição de um cargo; habilidade de dirigir um negócio; e o conjunto dos líderes de um determinado lugar ou organização (ROST, 1991, pp.37-67).
} 
A literatura secular de estudos de liderança tem início nos anos $1930^{4}$ - e frequentemente os manuais de liderança para administração e/ou psicologia social contam uma história linear de sucessão de teorias desenvolvidas no âmbito destes dois campos de conhecimento, ignorando o desenvolvimento de estudos em outras áreas, como história, ciência política, história militar, ciências da saúde, educação, sociologia, antropologia, dentre outros. Atualmente, boa parte dos livros sobre liderança na área de administração e psicologia ainda traz características de teorias supostamente "superadas", quando o tema da liderança ganha interesse renovado no Brasil e nos Estados Unidos.

Nestes livros estão entrelaçadas em maior ou menor grau as seguintes teorias: a teoria dos "grandes homens", predominante no século XIX - e que se alia à visão positivista de história política, militar e diplomática levada por poucos notórios personagens, que asseguram o progresso da história. Presente nas biografias e autobiografias, a teoria dos grandes homens foi rechaçada pelos psicólogos e administradores a partir dos anos 1930, mas ganhou interesse renovado nos anos 1980, em especial com as biografias e autobiografias de grandes executivos e personalidades, num período em que a economia norte-americana e a grande mídia exaltavam os "yuppies", os homens de negócio do mercado financeiro e das grandes companhias. Teorias dos traços (predominante nos 1930-1940), comportamentais ou behavioristas (mais vigente nos anos 1940 e 1950), situacionais/contingenciais (1960-1970), transformacionais (1970-1980) e de excelência (1980) também se entrecruzam em obras que procuram ensinar seus leitores e estudantes como atingir a maior eficácia no seu trabalho.

Rost afirma que a década de 1980 assistiu a uma explosão da indústria da liderança, com um número quase triplicado de livros publicados em relação à década de $1970^{5}$. Thomas E. Frank

\footnotetext{
${ }^{4}$ Para se ter uma noção do alcance acadêmico dos estudos de liderança, o primeiro centro de estudos de liderança é fundado nos anos 1940 - The Ohio State Leadership Studies, seguido do Michigan Studies of Leadership nos anos 1950. O Centro para Liderança Criativa (The Center for Creative Leadership) tornou-se a maior força no treinamento e na aplicação de pesquisa em administração. O primeiro programa de doutorado em estudos de liderança foi fundado na Universidade de San Diego em 1979, e o primeiro curso de graduação em liderança foi iniciado em 1992, na Universidade de Richmond. Além disso, houve expansão da pesquisa sobre o tema na Europa, Japão, Israel e Índia a partir dos anos 1970. Até 1987, segundo Bass (1991), cerca de 600 universidades ofereciam cursos sobre o tema, além de cursos de treinamento para liderança comunitária serem bastante oferecidos por todo o país. Para maiores informações sobre essa área consultar Stogdill (1974), Bass (1981). Para maiores informações sobre essa área consultar Bass (1981).

${ }^{5}$ Rost levantou 587 livros, capítulos de livro e periódicos produzidos entre 1900 e 1979 - parte deste levantamento foi consultada em Bass (1981); e 312 publicações do mesmo tipo lançados na década de 1980. Entre 1900 e 1909, foram encontradas três publicações; entre 1910 e 1919, apenas uma; entre 1920 e 1929, foram lançadas 12 publicações; entre 1930 e 1939, 13 publicações; entre 1940 e 1949, 19 publicações; entre 1950 e 1959, 40
} 
(2002) afirma que o interesse massivo em liderança nos EUA nos anos 1980 foi uma resposta ao contexto político e econômico no qual os EUA se encontraram. Frente à percepção de que os EUA não eram mais os líderes mundiais de outrora, a liderança torna-se uma narrativa mitológica que confere conforto, esperança e segurança de que "tudo está bem", porque existem líderes que podem salvar companhias, sociedades, países e até o mundo (ROST, 1991, p. 7-8). Bastava seguir aquilo que os experts demonstram ser cientificamente comprovado. Rost (1991, p. 29) defendeu que o interesse em liderança não é uma resposta efetiva a um problema real, mas uma mitologia que ajudaria os americanos a acalmarem seus medos diante das incertezas, independente de esta solução ser eficaz ou não.

A sua longevidade se deve ao que Rost denomina de "paradigma industrial do conceito de liderança", o que explica a sua reprodução em diversos veículos, reciclando terminologias e metodologias desde os anos 1930, a fim de ensinar a qualquer pessoa que é possível ser um líder e vencer na vida. Tal paradigma explica a identificação de liderança como sinônimo de administração ou gerência. Assim, a boa liderança é entendida como boa administração, sendo: "racional, orientada para a administração, masculina, tecnocrática, quantitativa, voltada para o cumprimento de metas, atenta à relação custo-benefício, personalista, hierárquica, com visão de curto prazo, pragmática e materialista" (tradução livre, idem, p. 94). Tais características serviriam para "amenizar as realidades existenciais de se viver numa cultura democrática em que as pessoas acreditam que um elevado padrão de vida é seu direito de nascimento, mas que tais realidades não se encaixam muito bem ao que é prometido" "(tradução livre, idem, p. 94).

A partir dos anos 1970 acentua-se a Divisão Internacional do Trabalho, e multinacionais ganham projeção em várias partes do mundo, incluindo o Brasil. Na América Latina, os anos 1980 são conhecidos como "a década perdida", por conta da recessão e da hiperinflação. E também o período da maior introdução de certa "cultura corporativa", pela popularização de livros americanos traduzidos de liderança e gerência. A narrativa mitológica a que Rost se refere,

publicações; entre 1960 e 1969, 51. A partir da década de 1970 há um crescimento maior - entre 1970 e 1979, foram lançadas 136 publicações, e entre 1980 e 1989, 312 (ROST, 1991, p. 46).

${ }^{6}$ No original: "Analyzed individually and in toto, the leadership definitions reviewed in these chapters reveal a fundamental understanding of leadership that is rational, management oriented, male, technocratic, quantitative, goal dominated, cost-benefit driven, personalistic, hierarchical, short term, pragmatic, and materialistic" (ROST, 1991, p.94).

${ }^{7}$ No original: "These expressive characteristics soothe the existential realities of living in a democratic culture wherein people believe that a high standard of living is their birthright but the realities do not quite match the promise" (ROST, 1991, p. 94). 
e que é reproduzida até os dias atuais em materiais de treinamento de administração ${ }^{8}$ visa promover segurança no funcionamento do sistema de pesquisa, feito para aperfeiçoar $o$ conhecimento e a prática da liderança, para que as organizações sejam mais produtivas e que, assim, o país (no caso, os Estados Unidos - mas podemos pensar cada qual em seu país), e o mundo seriam um lugar melhor para se viver (ROST, 1991, p. 32). Tal mitologia possui seus rituais - escolas de administração e psicologia, organogramas, treinamentos, palestras, questionários, testes, coletâneas de textos básicos, e mesmo os livros mais populares se encaixam nesta lógica.

Estariam os livros de liderança com a figura de Jesus inseridos nesta lógica? Em parte, sim - questionários de performance e avaliação estão presentes em livros como "Como se tornar um líder servidor", de James C. Hunter (2006). Ao mesmo tempo, em apostilas mais recentes sobre liderança secular, valores éticos e morais perpassam as características que os líderes devem demonstrar, a fim de não serem meros gerentes, como as apostilas de MBA (Mestrado em Administração de Negócios). Elementos de liderança servidora têm aparecido nos materiais mais recentes de treinamento e em livros populares de liderança, enfatizando a necessidade do líder em apresentar bom caráter, conduta ética irrepreensível, cultivo de valores morais, amor à equipe e bom convívio.

Para entender como ocorrem os encaixes e desencaixes destes discursos seculares e religiosos ou morais, do seu contexto original norte-americano, para o Brasil, em período um pouco posterior, observamos que até os anos 1970 havia poucos livros sobre liderança, e em sua maioria na área de administração e psicologia, traduzida dos EUA. Livro sobre liderança religiosa ou liderança baseada em alguma figura religiosa, não foi encontrado. Porém, a partir dos anos 1980, e mais acentuadamente nos anos 1990 e 2000, houve um crescimento sem precedentes de livros sobre liderança, com apelo mais popular. E a partir do final dos anos 1990 e ao longo dos anos 2000 livros sobre liderança baseados em figuras religiosas - mais notadamente Jesus Cristo - traduzidos do inglês chegam ao Brasil. Se reconhecemos este movimento de chegada desta tendência, não encontramos algo autóctone no Brasil anterior a este período. Os principais

\footnotetext{
${ }^{8}$ Cf. material instrucional de cursos de MBA produzido pela Fundação Getúlio Vargas, uma das instituições mais procuradas neste campo. Na Apostila de Março de 2011 sobre Liderança e Inovação, encontram-se os seguintes temas: Módulo 1 - A liderança e a inovação no mundo contemporâneo; Módulo 2 - Habilidades decisórias: razão, visão e a intuição como recursos gerenciais. Módulo 3 - Habilidades na gestão da influência - o uso positivo do poder e da autoridade; Módulo 4 - Habilidades interpessoais - objetivo comum e a corretagem do poder (MOTTA, 2011).
} 
agentes de tradução foram editoras evangélicas e algumas editoras seculares com forte apelo em livros inspiracionais, como a Sextante.

No caso de produções baseadas na figura de Jesus, há muitos livros lançados entre os anos 1990 a 2010, seguindo um crescimento que se inicia nos anos 1980. A literatura de liderança que visa a um público amplo de leitores e clientes, que se interessa em se instruir na arte da liderança a partir de exemplos e valores religiosos e/ou espirituais. Tal produção investe em modelos de liderança baseados nas palavras e nas ações de Jesus Cristo, misturando uma série de teorias presentes no arcabouço simbólico e narrativo da liderança no Ocidente. Um exemplo que tem se destacado é o modelo de liderança servidora, que foi sistematizado pela primeira vez por Robert Greenleaf, em 1970, e desde então tem sido apropriado por diferentes autores. Para Rost, o modelo de liderança servidora é uma alternativa em relação aos modelos dominantes na área de administração e psicologia social, ao enfatizar não o líder, mas os liderados. Já para Frank (2002), no contexto da incorporação de teorias de liderança pelas igrejas evangélicas, a liderança servidora entra em paradoxo com a lógica de fazer a igreja crescer em discípulos.

Muito do que Rost identifica como discurso dominante nos estudos de liderança até os anos 1980 tem sido modificado a partir dos anos 1990 e 2000. A popularidade de livros como "O monge e o executivo" (HUNTER, 2004), que retomam a liderança servidora, demonstra que a liderança tem se adaptado a ideais de relacionamentos mais humanizados nos ambientes de trabalho. Observa-se a imbricação de valores religiosos, espirituais e morais com aspectos do

\footnotetext{
${ }^{9}$ Dentro desta bibliografia, destacamos os seguintes títulos: "O estilo de liderança de Jesus", de Michael Youssef (1986); "Jesus C.E.O.” (1995) [no Brasil, saiu como "Jesus, o maior líder que já existiu”, e "Jesus C.E.O.”] , “Jesus , Inc.: the Visionary Path" (2001), e "Jesus: Life Coach - Learn from the Best" (2006), de Laurie Beth Jones; "Lições de liderança de Jesus - o melhor líder de todos os tempos tem algo a dizer para você", de Ray Pritchard e Bob Briner (1997); "Os segredos da liderança de Jesus - 58 chaves da sabedoria que podem trazer milagres que você jamais experimentou", de Mike Murdock (2005); "Jesus - o maior executivo que o mundo já viu”, de Charles Manz (2006); "The emotional intelligence of Jesus : relational smarts for religious leaders", de Roy M. Oswald e Arland Jacobson (2015); "12 leadership lessons from the life of Jesus Christ" de Kimball Fisher (2016), dentre outros. Neste capítulo enfatizaremos de maneira aprofundada o livro de Robert K. Greenleaf (1970) e o livro Blanchard e Hodges (2007), com breves comentários a outras produções por conta do espaço. Vale ressaltar que notamos um crescimento na oferta de títulos que não somente tomam Jesus Cristo como modelo de liderança (dentro de diversas teorias da liderança), como outras figuras bíblicas e religiosas não cristãs. Além disso, um número crescente de obras que lidam com questões emocionais, religiosas e espirituais no ambiente de trabalho, na gestão corporativa e no mundo dos negócios tem crescido de forma mais acelerada nos Estados Unidos, tendo algum reflexo no Brasil. Destacamos produções como: "Espiritualidade no mundo corporativo: aproximações entre prática religiosa e vida profissional", de Ed René Kivitz (2007); "Maximizing the triple bottom line through spiritual leadership", de Louis W. Fry e Melissa Sadler Nisiewicz (2013), "Fostering spirituality in the workplace [electronic resource]: a leader's guide to sustainability", de Priscilla Berry (2013); "Evangelical Christian executives: a new model for business corporations", de Lewis D. Solomon (2004); "Spirituality in management: means or end?", de S.K. Chakraborty e Debangshu Chakraborty (2008), dentre outros.
} 
mundo corporativo e administrativo: se ser líder significa exercer influência sobre outras pessoas, por que não exercer uma influência positiva, através do cultivo de um bom relacionamento e da manutenção de um caráter irrepreensível? A oportunidade de ser líder deve ser aproveitada para que novos líderes se formem, e o bom exemplo, calcado na Regra de Ouro e/ou em Jesus Cristo, reproduza-se infinitamente de dentro para fora da organização.

Mas é importante perguntar: por que livros de liderança que se baseiam justamente em Jesus Cristo? Além de Jesus ser uma das personalidades mais conhecidas mundialmente há séculos, existem razões que explicam a escolha de Jesus, em detrimento de outras figuras, como Davi e Salomão, também tidos como grandes líderes dentro desta lógica.

\section{AS LIDERANÇAS DE JESUS}

Uma pista para entender porque tantas figuras díspares, como Jesus, Jack Welsh, Madre Teresa e Átila, o Huno, viram modelo de liderança é o que Rost (1991, p. 6) identificou como um problema nos estudos de liderança - a falta de definição sobre o que é liderança - muitos livros definem liderança pelas características dos líderes (teoria dos traços; teoria dos grandes homens/mulheres), outros, pela relação entre liderança e seguidores (estilos de liderança), outros pelas situações em que a liderança ocorre. Esta condição permite entender porque tantos modelos e tantas estratégias de liderança continuam se reproduzir, seja no âmbito acadêmico, seja no âmbito da literatura mais popular.

No prefácio para a edição brasileira do seu mais recente livro, "De volta ao mosteiro" (2014), o escritor norte-americano James C. Hunter afirma que cerca de $80 \%$ das vendagens dos seus dois títulos anteriores - "O Monge e o Executivo" e "Como se tornar um líder servidor" ocorreram no Brasil. Estes livros trazem a figura de Jesus Cristo como modelo de liderança servidora, juntando-se a outros títulos de autoria norte-americana nos últimos trinta anos, que se utilizam do exemplo da vida de Jesus como receita para o sucesso como liderança.

Os discursos midiáticos sobre liderança e sucesso produzidos no âmbito cristão, trazem representações históricas de Jesus advindas da cultura protestante norte-americana, que circulam para além de seu contexto de produção. Chegam ao Brasil traduzidos sem notas explicativas sobre especificidades da realidade norte-americana referenciada nos textos. Contudo, ancoram-se numa figura que aparentemente não necessita de tradução - Jesus Cristo. Nesse sentido, essa 
produção aciona categorias identitárias e símbolos religiosos que pertencem a um arcabouço cultural, a uma "caixa de ferramentas" religiosas que servem de suporte para aliar o passado e o presente nas mais recentes encarnações da figura de Jesus.

O historiador Stephen Prothero (2004) afirma que a centralidade da figura de Jesus na cultura religiosa americana criou um denominador religioso comum entre protestantes de diferentes vertentes, sendo o personagem bíblico mais importante a ser abordado na virada do século XIX para o século XX. No seu estudo “American Jesus" (2004), o historiador analisa como Jesus tornou-se um ícone norte-americano, ao ser despido de teologias e doutrinas por uma parte importante da cultura protestante americana.

Toda uma tradição protestante se sucedeu, retratando Jesus mais como um ser humano extraordinário do que uma divindade encarnada. Isso permitiu que outras vertentes cristãs no século XIX e no início do século XX se apropriassem de Jesus à sua imagem e semelhança, encarnando papéis os mais diversos, dentre eles, o de líder.

A roupagem de líder seguiu inicialmente o "cristianismo muscular" entre 1880 e 1930, encampado por setores masculinos protestantes tanto nos Estados Unidos quanto na GrãBretanha, como reação à feminização da religião e de Jesus ao longo do século XIX. Neste contexto surge um dos mais marcantes retratos de Jesus como líder viril, "The man nobody knows" (BARTON, 1925), escrita pelo publicitário e protestante Bruce Barton. A personalidade magnética e popular do homem Jesus, filho de um carpinteiro, acostumado à vida ao livre e ao trabalho pesado, que lidava com pessoas de diferentes escalas sociais; másculo, de físico e caráter fortes, empreendedor e altivo. Segundo Barton, as características que permitiram o sucesso de Jesus também serviriam para qualquer leitor nos dias contemporâneos - a crença em seu potencial, a vontade de superar seus problemas e suas limitações, e o desenvolvimento de suas qualidades. O conceito protestante que unia o progresso material ao espiritual (PROTHERO, 2004) pautava-se em um Jesus passível de ser apreendido e seguido nos dias modernos, por estar privado de boa parte de seus poderes sobrenaturais.

Desta forma, vemos a existência de tantas representações de Jesus, feitas para torná-lo exemplo de algo, ao longo do século XX: líder, professor, psicólogo, mestre dos mestres, revolucionário, conservador. Os norte-americanos não iniciaram estas apropriações, pois elas fazem parte do imaginário cristão, se adotarmos o recorte da longa duração. Mas a especificidade norte-americana reside no seu ímpeto missionário e na cultura impressa e no mercado de bens 
cristãos difundidos conjuntamente à mundialização da cultura no século XX. A figura de um Jesus líder empreendedor sanciona a condição de existência de crenças e práticas religiosas que pregam a abundância, a prosperidade espiritual e material, o sucesso como meta de realização de vida. Por outro lado, o modelo de liderança de Jesus não é unívoco, e a liderança servidora reatualiza a figura de Jesus no último quartel do século XX.

O conceito de liderança servidora enfatiza determinadas características de Jesus Cristo e de seu ministério descrito nos evangelhos a fim de oferecer aconselhamento para uma liderança ética dentro do contexto da globalização, da divisão internacional do trabalho, do ideário yuppie e pós-yuppie, da cultura corporativa pós-industrial. Se os manuais de gerência possuíam um objetivo específico de treinar para certas funções numa empresa, os livros sobre liderança assumem uma linguagem grandiosa e, não raro, religiosa: o líder tem uma missão, uma visão, um sonho a ser realizado. Ele é magnético, popular, sensível às necessidades dos seus liderados; cultiva a habilidade de ouvir os outros e encontrar a melhor solução em conjunto com a equipe. $\mathrm{O}$ sujeito é oculto - aqui e ali, em todos os livros lidos, encontramos lembretes de que esse modelo de Jesus serve para várias situações de liderança, dentro da família, na escola, no trabalho; podem ser homens e mulheres; mas, sendo o sujeito oculto, ele é implicitamente masculino. Thomas Frank defende que, quando o líder é incentivado por estes manuais a trabalhar com as emoções (usando o conceito de inteligência emocional, por exemplo) nas relações com os seus seguidores ou liderados - ou subordinados - tal iniciativa é vista como positiva quando feita pelos líderes masculinos, pois demonstraria nobreza de caráter (em geral porque são demonstrações de emoções como benevolência e empatia). Mas se demonstradas por líderes femininas, ainda são recebidos como sinais de fraqueza (FRANK, 2002).

Ele surge em um contexto em que elementos de espiritualidade e fé são instrumentalizados no ambiente de trabalho e nos negócios, seja nos Estados Unidos, seja pelo mundo afora, de forma visível e organizada a partir dos anos 1980, no que David Miller (2007) denomina de Movimento de Fé no Trabalho (Faith at Work Movement). Mas antes que se articulasse esse movimento, surge o conceito de liderança servidora, que terá desdobramentos diversos desde então. 


\section{AS LIDERANÇAS SERVIDORAS}

O primeiro escritor a desenvolver o conceito de liderança servidora foi o norteamericano Robert K. Greenleaf (1904-1990), no ensaio "The servant as leader" de 1970, sob influência do livro "Journey to the East", de Herman Hesse. Neste ensaio, Greenleaf cita Jesus Cristo em apenas uma passagem, que se refere à capacidade do líder em manter distanciamento das tensões e conflitos, para tomar a decisão certa - o que se verificou na história da mulher adúltera. Jesus era um líder com o objetivo de trazer mais compaixão para o mundo. Citando até a "Pedagogia do Oprimido", de Paulo Freire, Greenleaf não traz um passo a passo para uma liderança eficiente, mas sim um ensaio filosófico sobre a importância de servir em primeiro lugar em qualquer instância ${ }^{10}$. Os problemas do mundo são causados pelas (más) escolhas dos indivíduos, por não servirem aos seus próximos. A liderança servidora, para Greenleaf, é uma nova concepção de liderança a ser adotada por todos, em especial pelas "pessoas de pele escura, pelos desprivilegiados, pelos alienados da sociedade" (1970, pp. 19-20), que encontrariam sua própria voz e sua própria liderança para conduzir suas vidas, sem a interferência das elites privilegiadas. No período em que escreve, ocorriam os movimentos pelos direitos civis dos afroamericanos, além dos movimentos de libertação nacional em curso desde os anos 1950 em várias partes da Ásia e da África.

O autor escreveu este ensaio após observar as revoltas estudantis e a contracultura juvenil nos Estados Unidos no final dos anos 1960. A nova geração rejeitaria o conceito antigo de liderança, baseada na coerção e no poder hierárquico, e estaria mais preparada para uma nova prática de liderança, voltada para a formação de pessoas e, não, para a manutenção do status quo.

O texto é repleto de ideias retiradas do vocabulário religioso e do domínio das emoções - o que torna um período histórico fértil ou não para a visão profética é o interesse e a resposta de quem a percebe (GREENLEAF, 1970, p. 3); o líder possui inspiração, intuição, visão e iniciativa para apontar o caminho a ser seguido, sensibilidade e consciência para pensar e agir de forma criativa. O ensaio de Greenleaf apresenta um prognóstico - o mundo está numa crise de liderança, em tempos de injustiça, hipocrisia, corrupção. A solução é a liderança servidora - o

\footnotetext{
${ }^{10}$ A citação à obra de Freire demonstra que a versão disponível on line é a revisada de 1973, que só veio a ser publicada novamente em 2003, por iniciativa de Larry Spears (ver: FEARCH et al., 2015).
} 
servidor-líder coloca em primeiro lugar as necessidades dos outros e, ao fazer isso, todos se tornam mais saudáveis, mais sábios, mais livres, mais autônomos ${ }^{11}$.

No $25^{\circ}$ aniversário (em 1995) de lançamento de "Liderança servidora" de Greenleaf, Stephen Covey, outro especialista em liderança, escreve no prefácio:

Devido ao fato de trabalhar em nações de diferentes culturas e religiões, eu tenho visto essa consciência universal revelar-se uma e outra vez. Existe realmente um conjunto de valores, um senso de integridade, honestidade, respeito, e contribuição que transcende culturas, algo que é atemporal e transcende as eras e é também auto-evidente. É tão auto-evidente como o fato de que se requerem pessoas dignas de confiança para gerar confiabilidade (COVEY apud GREENLEAF, 2002).

Covey aponta a atemporalidade e o caráter auto-evidente de valores apreciados pelas empresas e pelos trabalhadores nas diversas culturas que se interligam pela globalização. Face um fenômeno histórico tão recente e tão avassalador, elementos do vocabulário religioso e moral são acionados por diferentes autores, com ou sem o modelo da figura de Jesus Cristo, a fim de estabelecer uma gerência das emoções e da moral no ambiente de trabalho.

Desde o final dos anos 1990, Kenneth Blanchard (1939-) desenvolve o conceito de liderança servidora em seus livros, dentre eles, destaca-se "Lidere como Jesus: lições do maior modelo de liderança de todos os tempos” (2007), escrito com Phil Hodges. Blanchard já era conhecido escritor de livros de gerência, por conta de "O Gerente minuto - Guia prático do executivo moderno" 12 (1981), escrito com Spencer Johnson, autor de outro best-seller - "Quem

\footnotetext{
${ }^{11}$ Greenleaf trabalhou por três décadas na companhia telefônica AT\&T, e após a aposentadoria fundou o Centro de Ética Aplicada (Center for applied ethics), rebatizada em 1985 de Centro Greenleaf de Liderança Servidora (Greenleaf Center for Servant Leadership). Nos anos 1970 Greenleaf lançou The institution as servant (1972), The trustees as servants (1974) e Servant Leadership: A Journey into the Nature of Legitimate Power and Greatness (1977). No site do Greenleaf Center, outros autores são apontados como contemporâneos ou seguidores do conceito de liderança desenvolvido por Greenleaf - Ken Blanchard, Stephen Covey, Larry Spears, dentre outros - porém, nenhuma referência a James C. Hunter, autor de "O Monge e o Executivo" (2004). Greenleaf também atuou como consultor da Lilly Endowment, uma das fundações que mais financia projetos nos Estados Unidos, e segundo Larry Spears (FEARCH et allii., 2015, p. 85), isso resultou em um maior financiamento de projetos que incentivassem a liderança servidora em seus conselhos e suas estruturas nos anos 1970.

${ }^{12}$ O livro "O gerente minuto" gerou outros "rebentos", como é comum no universo editorial norte-americano - "A liderança e o gerente-minuto" (escrito com Patricia e Drea Zigarmi, e também publicado no Brasil), assim como "The fourth secret of the One-minute manager" e "The One Minute Apology: A Powerful Way to Make Things Better (2003), com Margret McBride; "The One Minute Entrepreneur: The Secret to Creating and Sustaining a Successful Business", com Don Hutson e Ethan Willis (2008); "The One Minute Manager Balances Work and Life", com D. W. Edington e Marjorie Blanchard.(1999); "The One Minute Manager Meets the Monkey", com Hal Burrows e Willam Onken Jr. (1991). Na linha mais religiosa, Blanchard lançou o livro "The generosity fator", com o fundador da cadeia de fast-food Chic-fil-A, S. Truett Cathy, conhecido por adotar princípios cristãos em sua empresa.
} 
mexeu no meu queixo?". Desde os anos 1960 trabalhava na área de administração e recursos humanos, e fundou a empresa de treinamento e consultoria The Ken Blanchard Companies e posteriormente, fundou The Center for FaithWalk Leadership nos anos 2000, conhecido como o título de seu livro - "Lidere como Jesus" (Lead Like Jesus ${ }^{13}$ ), que possui material instrucional, palestras, cursos e escritórios internacionais pelo mundo, além de site próprio e página no Facebook com reflexões frequentes diárias de seus seminários e de seus frequentadores.

No prefácio ao livro Focus on leadership (2002), revela que em entrevista ao reverendo Robert Schuller, em 1983, para promover "O Gerente-minuto", o pastor observou que Jesus podia ser visto como o gerente-minuto. Ficou intrigado com a comparação, mas foi somente no final dos anos 1980 estudar de fato a Bíblia e o ministério de Jesus Cristo, por influência do amigo Phil Hodges, e quando escreveu o livro "O poder da administração ética", com Norman Vicent Peale. Em "Lidere como Jesus", Blanchard afirma:

Tudo o que eu tinha ensinado sobre liderança, durante os últimos 35 anos, Jesus tinha feito com uma perfeição extraordinária. Percebi que, mais do que uma liderança espiritual, Jesus oferece um modelo de liderança prático e eficiente para todas as organizações, para todas as pessoas, para todas as situações (BLANCHARD \& HODGES, 2007, p. 13).

O objetivo do livro "Lidere como Jesus" é permitir que o leitor vivencie Jesus de uma maneira "totalmente diferente do que já experimentou", pois Jesus quer que "deixemos uma marca transformadora no mundo aos bons tornarmos líderes servidores" (BLANCHARD \& HODGES, 2007, p. 13). As situações em que esta liderança pode ser aplicada são várias - pode ser tanto a liderança nos negócios quanto os relacionamentos pessoais em qualquer organização, "transformando o comportamento das pessoas na empresa ou na família" (idem).

Diferente do modelo servidor de Greenleaf, esta publicação reforça uma identidade cristã devocional, visando não somente dissecar os princípios da liderança servidora presente nos atos e as palavras de Jesus nos Evangelhos, mas também despertar nos leitores uma disposição para a adoração e para o cultivo de uma relação pessoal com Deus. Dentre os sete passos para aproveitar melhor o livro, destacam-se: "Comece com uma oração dirigida a Deus - à energia universal criadora, para que a leitura do livro leve à transformação" (idem, p. 14). Outros passos 13 Para maiores informações sobre o ministério Lead Like Jesus, consultar o site oficial:
https://www.leadlikejesus.com/. Acesso em 16 de fevereiro de 2016. 
visam estimular o estudo dirigido do livro - sublinhar conceitos, fazer resumos e observações, refletir como seus conceitos podem fazer do leitor um líder melhor; compartilhar com outras pessoas o que aprendeu e reavaliar seu progresso periodicamente, pedindo retorno às pessoas que lidera sobre o seu desempenho (idem, pp. 14-15). Ao final de cada capítulo, há a seção "Pare e Reflita", com perguntas e versículos bíblicos que visam relacionar o conteúdo do capítulo às experiências e às opiniões dos leitores.

O prognóstico dos autores sobre o contexto do mundo atual indica que ele precisa de um modelo diferente de liderança, frente aos escândalos, aos valores abandonados, traição, exploração e manipulação presentes nas notícias da mídia. Além disso, há uma descrença quanto às lideranças nos governos, empresas, igrejas, esportes, famílias; nas empresas as motivações dominantes são o dinheiro e o poder; nos relacionamentos, predominam o orgulho, o egoísmo, o medo e a indiferença. Mas Jesus oferece um modelo de liderança que respeita o ser humano e promove a saúde e a eficácia em organizações e relacionamentos. (idem, p. 17).

Jesus possuiu uma qualidade inata de líder, e também passou por inúmeros desafios diários na vida e no trabalho, conhecendo os "problemas que nos atormentam no mundo atual (...) imagine como Jesus faria o trabalho que você desempenha ou lidaria com as pessoas de sua família" (idem, p. 29). Para liderar como Jesus é necessário seguir quatro instâncias da liderança, assumindo um compromisso de liderar de forma diferente (idem, p. 31): primeira, a liderança pessoal, isto é, conhecer a si próprio como alvo do amor incondicional de Deus - o sucesso do indivíduo depende do seu relacionamento com Cristo (idem, pp. 33-34). Segunda, a liderança individual, ou seja, a construção da confiança diante dos seus seguidos mais próximos, tal como Jesus fez com seus discípulos, evitando a visão egocêntrica. Terceira, a liderança de equipe ou família, que respeita as características individuais e estimula o trabalho em grupo - após ensinar seus discípulos, Jesus enviou-os em duplas para construir a confiança e a eficácia da missão. As circunstâncias externas não interferem tanto no sucesso de uma organização quanto a sua constituição interna. Se esta for sólida, nenhum problema a abalará.

No vocabulário secular dos estudos de liderança, Blanchard e Hodges apostam num modelo de liderança relacional e transformacional, em que impera a relação entre liderança e liderados. As teorias contingenciais inserem as situações externas como fatores determinantes para a liderança. Contudo, a preferência por um modelo relacional permite sua aplicação a qualquer situação, independente de quem estiver envolvido, pois o sucesso ou o fracasso desta Fronteiras: Revista de História | Dourados, MS | v. 19 | n. 34 | p. 207 - 233 | Jul. / Dez. 2017 
relação está nas mãos de quem está nela. É um recurso útil para a obra exercer apelo em um público amplo, sem correr o risco de se tornar datada. A chancela da presença de Jesus, corroborada pelas passagens bíblicas, visa trazer solidez e atemporalidade aos exemplos e às situações abordadas.

A quarta instância é a liderança organizacional ou de comunidade. Jesus preparou os discípulos nas três primeiras instâncias para que eles dominassem a quarta após a sua morte. Esta instância ensina que é preciso atentar tanto para os relacionamentos quanto para os resultados. Além disso, é preciso encontrar interesses comuns para unir as pessoas com diferentes opiniões, expressar o amor com sinceridade, coragem, boa vontade, tolerância e integridade, e tomar decisões com base em princípios éticos - escolher o que é correto, respeitar os outros, solidarizarse com quem sofre, reconhecer quem se dedica e compreender os diferentes (idem, pp. 37-42).

Em alusão aos princípios de "O Gerente-minuto", os autores afirmam que quem possui "um coração servidor e uma visão de liderança voltada para servir" poderá "promover o crescimento de quem está sob sua responsabilidade, definindo objetivos claros, valorizando os progressos e redirecionando com serenidade e afeto os comportamentos inadequados" (idem, p. 43). Em "O Gerente-minuto" (1981), três ações - "três segredos" - guiam a liderança eficaz: os objetivos-minuto (o estabelecimento e a comunicação de objetivos claros para os subordinados); os elogios-minuto (elogiar quem executa as tarefas conforme as instruções), e as repressõesminuto (apontar de forma serena e assertiva o que não saiu como esperado, sem ofender o subordinando, mostrando como corrigir o erro). Mas para chegar a este estágio, na versão cristã do gerente-minuto, é preciso que o coração esteja transformado através do relacionamento com Deus. Assim, ser um servidor significa também estar a serviço de Deus, pois ele procura pessoas para construir um "reino de justiça e amor - o Reino de Deus" (BLANCHARD \& HODGES, 2007, p. 52).

Trata-se de um reino divino em que a eficiência não é deixada de lado, uma qualidade da liderança bastante apreciada dentro do paradigma industrial da liderança. Um termo muito comum em manuais de liderança nos anos 1980 foi "excelência" - e a liderança servidora pode resultar nisso: "A excelência da liderança do servidor se concretiza quando a próxima geração de líderes é capaz de enfrentar os desafios de seu tempo $\mathrm{cm}$ toda a sabedoria, conhecimento e recursos espirituais que o líder forneceu” (idem, p. 103). Em outro livro, Blanchard reafirma a eficácia da liderança servidora: 
Sinceramente acredito que a liderança servidora nunca foi mais aplicável ao mundo da liderança quanto é hoje. Não somente as pessoas estão buscando um propósito e um sentido mais profundo quando devem enfrentar os desafios de um mundo em transformação; elas estão buscam princípios e filosofias que de fato funcionem. A liderança servidora funciona. A liderança servidora consiste em promover as pessoas a um nível mais alto ao liderá-las a partir de um alto nível. (tradução livre, BLANCHARD apud SPEARS \& LAWRENCE, 2002, p. XII).

Ao longo do livro "Lidere como Jesus", princípios desenvolvidos em trabalhos anteriores de Blanchard na liderança e na administração retornam como ensinamentos sistematizados que possuem correspondência com as passagens dos evangelhos. Em "O gerenteminuto" (1981), Blanchard e Johnson sistematizaram o modelo de Liderança Situacional II, desenvolvido para lidar com diferentes perfis de pessoa em uma posição de subordinado ou aprendiz. O líder ocupa-se em identificar o grau de maturidade e desenvolvimento de seus subordinados e estabelece com eles relações diferentes de comunicação e delegação de tarefas. Esses autores popularizaram a fábula sobre negócios, em que o gerente-minuto protagoniza uma situação hipotética, dentro de uma empresa fictícia, em que tem de lidar com diferentes tipos de subordinados, do novato ao mais experiente.

No "Gerente-minuto" há quatro estilos de liderança, que seguem estágios de aprendizado - e em "Lidere como Jesus" eles reaparecem em outros termos, mas seguindo a mesma ideia, tomando como exemplo o treinamento que Jesus fez com seus discípulos. O mesmo exemplo pode ser seguido pelos leitores de "Lidere como Jesus" para liderar as pessoas (BLANCHARD \& HODGES, 2007, pp. 113-127). Blanchard afirma que somente após a sua conversão é que ele notou que os conceitos da Liderança Situacional II eram "compatíveis com a forma como Jesus treinou e desenvolveu seus discípulos durante a trajetória percorrida por eles" (idem, 127).

Primeiro, há o estágio principiante - altamente comprometido, mas com baixa competência para executar as tarefas, por ser inexperiente. Por isso, necessita de uma supervisão mais atenta do líder responsável pelo seu treinamento. Em "O Gerente-minuto", isso se traduz em Estilo de liderança 4 (E4) para alguém com nível de desenvolvimento 1 (D1). Quando Jesus iniciou o treinamento de seus discípulos, dizia o que e como fazer (conforme Mateus 10: 5-13, 16). 
Segundo, há o estágio de aprendiz, quando alguém em treinamento apresenta motivação ou comprometimento baixo e alguma competência na execução de tarefas (D2). Necessita, portanto, de um estilo de liderança em que o líder demonstra mais apoio, elogio e encorajamento e menos direção (E3). Quando os discípulos de Jesus não conseguiram expulsar os demônios, Jesus não os repreendeu de forma ofensiva, dando a orientação necessária com amor (conforme Mateus 17: 18-20).

Terceiro, é o estágio do artífice (D3), que possui alta competência em suas tarefas e um comprometimento variável, necessitando da liderança maior apoio e menor direção (E2). Pedro era um discípulo artífice - ainda assim, ele afundou quando quis andar sobre as águas como Jesus, mas o seu mestre ainda assim lhe deu apoio para se manter de pé nas águas e voltar ao barco (Mateus 14: 26-30).

E o quarto estágio é o mais autônomo, quando o iniciante alcança, por meio da ação correta do líder, o status de mestre ou professor, com alta competência e alto comprometimento (D4), sendo-lhe plenamente delegadas as funções e tarefas pelo líder (E1). Trata-se do estágio em que os então liderados devem transmitir seus conhecimentos aos seus alunos/discípulos, e formar novos líderes. É o que os apóstolos realizam após a morte e ressurreição de Jesus Cristo.

Trata-se de um passo a passo aparentemente didático e racional, e que no caso do livro, poderia ser aplicado a qualquer situação que envolva um líder e um ou mais seguidores. Além dos exemplos bíblicos, são dados poucos exemplos de situações em que isso tenha sido de fato aplicado. Da mesma forma que "O gerente-minuto" demonstra estes princípios em forma de fábula, com uma situação hipotética, com líder e conjunto de liderados fictícios, em que a liderança se constitui na relação entre líder e liderados, sem interferência de outros fatores comuns no cotidiano de uma organização.

Este princípio também está presente em outros livros que tomam a liderança servidora como modelo - "O Monge e o Executivo" (HUNTER, 2004) e "Jesus C.E.O.” (JONES, 1996) não seguem os mesmos modelos de Blanchard e Hodges, mas também se centram na liderança relacional. Também são livros que trazem um modelo de liderança calcado no domínio das emoções. Blanchard e Hodges, no capítulo "Porque liderar como Jesus?", trazem argumentos também encontrados nos livros de Hunter e Jones - a liderança do servidor coloca em ação o amor de Jesus, ao ajudar os outros a serem as melhores pessoas que podem ser, que constroem o Reino de justiça e de amor (idem, p. 173). Fazer a melhor coisa requer paciência, sabedoria, 
coragem, sacrifício e empenho; mesmo que oscilemos entre palavras e ações, é importante manter a intenção de liderar como Jesus (idem, p. 173). A liderança servidora contradiz o espírito de nosso tempo, no início do século XXI, algo semelhante foi afirmado por Greenleaf no seu ensaio de 1970, ao dizer que a liderança servidora não era popular perante os eventos de sua época.

Seria a liderança servidora de fato contracultural? Uma diferença importante existe entre o libelo de Greenleaf e o modelo situacional de Blanchard e Hodges: ainda que ambos afirmem que a liderança servidora não se coaduna com os problemas e os vícios do seu tempo presente (seja 1970, seja 2005), Greenleaf esboça um projeto de sociedade que visa transformar a situação social, econômica, política, virando de ponta cabeça a ordem existente. Para ele, a liderança servidora não era uma realidade, mas se avizinhava no horizonte, e não tinha uma conotação explicitamente religiosa - sua fonte de inspiração foi um personagem de Herman Hesse, escritor envolvido com o budismo e com uma busca espiritual que era mais questionadora das instituições.

Já para Blanchard e Hodges, a liderança servidora é cristã, bibliocêntrica, e ambivalente - ao mesmo tempo em que contradiz o tempo presente para construir o reino de Deus baseado no amor, na justiça e no serviço, ele também é um instrumento de eficácia e excelência nas organizações - ela funciona. Dentre as razões práticas para se liderar como Jesus, os autores afirmam que ela produz resultados - a liderança servidora fornece o melhor serviço, pois tende a cuidar melhor dos relacionamentos com os clientes e colegas. Se não cuidar dos clientes, uma organização pode ser derrotada pela concorrente que o fizer: "Os líderes servidores constatam que os bons resultados da empresa são a recompensa que se recebe por cuidar dos empregados e clientes, criando assim as melhores condições de sucesso" (idem, p.175).

A liderança servidora também significa uma liderança melhor, pois ajuda a superar a incompetência, pois Deus qualifica os que são chamados - algo que ocorreu quando Deus escolheu Moisés, Maria, os apóstolos. Um líder servidor que não tenha competência necessária poderá construí-la com o tempo por meio de sua humildade e vontade de se qualificar. Tais líderes colaboram com os subordinados, criam ambientes férteis para novas soluções, e repelem comportamentos antiéticos (idem, pp. 176-177). Diferente de alguns livros que discutem uma antiga questão - a liderança é inata ou é aprendida? - a argumentação de Blachard e Hodges segue a de outros livros de liderança religiosa e secular, afirmando que a liderança está ao alcance de qualquer pessoa, e que ela deve ser usada para o bem comum. 
Ainda que ao longo do texto os autores façam referências a situações familiares, o cerne da argumentação favorece mais a aplicação do modelo em ambientes corporativos:

[...] as comunidades e as organizações dirigidas por líderes servidores tendem a funcionar bem porque se alicerçam em valores sólidos, onde o sucesso e o sentido de vida se confundem. Estimulados a servirem uns aos outros, e tendo princípios claros, as pessoas tendem a trabalhar com honestidade e ética (idem, p. 178).

Os autores alertam que se a cultura da organização em que o leitor trabalha não permite que se fale sobre Jesus (algo mais comum nos Estados Unidos do que no Brasil), o leitor pode demonstrar seu comportamento de líder servidor como o seu testemunho - "É até preferível que as pessoas se sintam sensibilizadas pelo seu modo de ser antes de saberem da razão. Se elas gostarem do que virem, estarão prontas para aprender" (idem, p. 188). É como se a liderança servidora funcionasse como a fé cristã em ação, pois a lógica da liderança servidora - servir os outros, colocar as necessidades dos outros em primeiro lugar, e formar novos líderes servidores assemelha-se a um trabalho missionário e evangelístico.

Os autores reforçam que liderar é influenciar as pessoas, e seguir o modelo de Jesus implica deixar um legado entre os que são influenciados pelos líderes servidores: "liderar como Jesus não é só um curso, é um estilo de vida" (idem, p. 180) que começa com a decisão do leitor em mudar. De alguma forma, ser um líder servidor dentro do modelo apresentado por Blanchard e Hodges significa ser contracultural - mas não muito. Oferece uma esperança a quem lê de que é possível se tornar alguém diferente, mais próximo de Deus, e com o poder de influenciar as pessoas para o bem. De quebra, pode melhorar a vida da empresa.

A figura de Jesus neste livro é a do líder humilde, servo de Deus pai. Na obra há mais referências a passagens bíblicas do que inferências da figura humana de Jesus, que nunca é chamado de Jesus Cristo e, sim, Jesus de Nazaré, ou simplesmente Jesus. Diferente de livros como "Jesus CEO", ou "The man nobody knows", a figura de Jesus, suas ações cotidianas ou seus relacionamentos não são recriados para reforçar esta ou aquela característica ou traço (como na teoria dos traços da liderança), mas são referenciados os acontecimentos relatados nos evangelhos, com a reprodução das passagens (traduzidas da Bíblia de Jerusalém na versão brasileira). A partir dos eventos retratados é que o exemplo de liderança de Jesus se torna visível para embasar os conselhos de Blanchard e Hodges. Os autores evitam mencionar sua filiação 
denominacional - Hodges é "profundamente cristão" e Blanchard, "convertido", e ambos tomam a figura do líder cristão servidor que poderia ser desempenhado por qualquer pessoa. Mas elementos primários da cultura evangélica norte-americana estão presentes na obra - aceitar Jesus como Senhor e Salvador; recorrer ao Espírito Santo para aclarar as ideias e dar inspiração; desenvolver uma relação íntima com Deus no dia a dia e dar testemunho de sua fé e de seus princípios no ambiente de trabalho, na comunidade, na família.

Há a reelaboração das diretrizes do Gerente Minuto e da Liderança Situacional II por todo o livro, até nas orações é possível encontrar tais referências nos pedidos de ajuda conforme os diferentes níveis de desenvolvimento do leitor. Blanchard, no início do livro, alinha o sucesso de Gerente Minuto a uma obra divina - a algo que não ocorreu por acaso, porque se conforma à maneira como Jesus liderou. Ainda assim, embora contenha passagens bíblicas, raramente as passagens são contextualizadas. A missão salvífica fica em segundo plano, ao se dar referência maior à missão de Jesus em espalhar sua mensagem para a construção do reino de amor e justiça na terra. Nesse sentido, vislumbra-se um princípio pós-milenarista, pois em vários momentos o conceito de liderança servidora é atrelado à realização do reino no aqui e agora. Não há a análise de casos específicos de empresas em que o princípio da liderança servidora tenha funcionado. $\mathrm{E}$ ainda que o princípio seja apresentado em termos empresariais, em exemplos esporádicos de relações de trabalho, o livro é feito para criar uma transformação interior que se reflete nas ações do leitor.

Ao afirmar que a liderança servidora não é uma teoria, mas um estilo de vida, os autores desincumbem-se de dar receitas específicas para esta ou aquela situação corporativa (ou familiar, ou comunitária) articulando seus conselhos em uma base behaviorista/comportamental que valeria para qualquer situação da vida, em qualquer estágio. Ao usar a Liderança Situacional II de forma implícita, ampliam o escopo e o apelo da mensagem da liderança servidora, pois mostram que o líder também pode ser um aprendiz ou artífice em diferentes estágios do seu trabalho ou de sua vida. Ao atrelar os problemas da liderança ao "medo tóxico" e ao "falso orgulho", indicam quais atitudes atrapalham a relação entre líderes e liderados.

Os autores tomam todos os seres humanos como iguais em ações e sentimentos - a psicologia comportamental apresenta-se como a visão definitiva de como as coisas funcionam nas organizações. Para ambientes hostis, funcionários desmotivados, desonestos, desorientados, a liderança servidora traz a solução, o exemplo, o início do caminho certo a ser traçado por líderes 
e seguidores. A bondade contagia, o bom exemplo ilumina a trajetória com objetivos-minuto específicos, curtos e exequíveis; os seguidores/funcionários/filhos ficam felizes pois se sentem valorizados. O triângulo hierárquico, concebido como símbolo do poder tradicional, com o presidente/líder da companhia no topo e os liderados/funcionários/clientes na base, inverte-se para agradar a base.

Em meio a esta dança geométrica, Jesus de Nazaré - não o Cristo - emerge como mestre da humildade e da liderança servidora, expondo sua humanidade em Getsemâni, sua serenidade nos momentos de reclusão e oração, sua paciência e habilidade de treinamento ao orientar doze homens inexperientes na tarefa de espalhar sua mensagem em sua ausência. Sua natureza divina é lembrada em algumas passagens, quando anda sobre as águas, multiplica pães e peixes, cura e expulsa demônios e ensina seus discípulos a fazerem o mesmo. Mas continua o Jesus de Nazaré a ser o exemplo de liderança, de serviço a Deus Pai. E ao mesmo tempo em que se reforça a humanidade de Jesus, a humanidade bondosa, compassiva e sábia, reforça-se o caráter sobrenatural da intervenção de Deus Pai e Deus Filho nos pensamentos, sentimentos, ações e hábitos dos pretendentes a líderes servidores, além do caráter eficiente da liderança servidora ela é boa porque funciona, é eficiente, beneficia a todos, é ética e limpa, comunitária e altruísta. São prescritas orações e ferramentas para que os leitores cultivem seu relacionamento íntimo com Deus e Jesus. Da mesma forma como o conhecimento sobre a liderança servidora é sistematizado em passos, itens e subitens, a espiritualidade (que nunca é nomeada desta forma no livro) é alvo de ferramentas de melhoramento e avaliação. Os objetivos-minuto estão lá para ajudar a avaliação de desempenho do neófito - em poucas linhas, ele compromete a se tornar um líder melhor. A liderança chega até a substituir a competência - pois a humildade do líder se encarrega de engajar toda a equipe a ajudá-lo, além de mobilizar o líder para a autoqualificação.

\section{CONSIDERAÇÕES FINAIS}

Que dizer de manuais que operam com objetivos tão amplos em um momento em que a especialização técnica é grande e a concorrência no mercado de trabalho é brutal? De fato, o mundo mais flexibilizado do trabalho criou a demanda por um profissional com várias habilidades e capacidade de se virar sozinho e se adaptar ao sabor das mudanças. Saber uma só competência não o qualifica para muito; cultivar a capacidade de aprender continuamente é mais 
valorizado e cobrado, ainda que não devidamente recompensado. De que forma este conceito de líder servidor, cunhado nos anos 1970 por Greenleaf vem a se articular com a vida do trabalho e/ou com os papéis de liderança talhados a partir desse período? A quem interessa o líder servidor e em especial o Jesus líder servidor?

Em um período em que o marketing social das empresas e o trabalho benemerente de grandes companhias servem de isenção fiscal para reforçar uma imagem positiva de "responsabilidade social", a liderança servidora de certa forma não parece mais tão transgressora quanto profetizava Greenleaf há mais de 40 anos. Porém, as implicações de servir aos outros - e aos clientes-, pode se traduzir em se dedicar ao trabalho intensamente. Caso contrário, o concorrente o fará. Pensar nos outros e não em si próprio não poderia se traduzir em "dar o sangue" e mais a alma pela companhia e para o trabalho flexível, que toma as horas de lazer do empregado? A figura de Jesus foi altamente humanizada para se aproximar a um ideal de liderança que se tornava a missão de vida do líder na corporação, ocupando sua cabeça, coração, e tempo disponível. Ao assumir como "estilo de vida", como antídoto dos valores egocêntricos do mundo, até que ponto a postura apregoada pelos gurus servidores não contribuiria para criar uma disposição de rendição total ao trabalho, ainda que exemplos ligados à família e à igreja fossem arrolados no livro?

Observamos como esta produção sobre liderança tem crescido nas últimas décadas, propondo uma gerência de comportamentos e sentimentos a fim de colocar em prática a liderança de Jesus, num jogo ambivalente de humanizar o ambiente de trabalho e satisfazer as exigências do mercado. A liderança servidora é um exemplo dentre vários que surgiram num longo histórico de modelos científicos de liderança estudados e receitados para o mundo das organizações - é o modelo mais recentemente adotado por autores cristãos evangélicos norte-americanos para figurar manuais, palestras, serviços de consultoria e coaching cristão. Nossa pesquisa continua a explorar esses diversos canais que visam oferecer aconselhamento a pessoas de dentro e de fora das igrejas para serem líderes e impactarem a sociedade. A liderança pregada nestes veículos é a mesma que encontramos nos livros? A quem ela serve e quais os seus propósitos? Se se trata de um movimento oriundo dos Estados Unidos, como tem corrido sua recepção no Brasil? Tem havido produção nacional para atender especificidades brasileiras?

Por ora, encerramos o texto com uma reflexão sobre a importância do estudo da relação entre religião e mídia. O veículo analisado foi basicamente o livro, que ainda possui um papel Fronteiras: Revista de História | Dourados, MS | v. 19 | n. 34 | p. 207 - 233 | Jul. / Dez. 2017 
crucial na divulgação de ideias, e na articulação de outros meios e serviços ligados ao aconselhamento de liderança. Em 1938, o teórico literário Kenneth Burke (1998, pp.593-598), abordou a literatura inspiracional, atualmente denominada de autoajuda ou de aconselhamento. Para Burke, toda literatura é um equipamento para a vida; quem lê um livro sobre como alcançar o sucesso, já deu o primeiro passo simbólico para tal. Esse tipo de literatura fomenta sonhos e desejos, de forma tal que os seus leitores vejam uma maneira de colocar em prática o que aprenderam - se o farão, é outra questão. Burke não acreditava que as pessoas se engajassem efetivamente em aplicar o que aprendiam: "o fascínio do livro reside no fato de que o leitor, enquanto lê, já vive a aura do sucesso. O que ele deseja é o sucesso fácil, e ele o encontra na sua forma simbólica pelo ato da leitura" (BURKE, 1998, p. 596).

A literatura religiosa de liderança também pode ser interpretada desta maneira - ela reforça uma narrativa mitológica advinda da literatura secular de liderança, e conforta seus leitores com uma possibilidade de exercer uma influência positiva sobre as pessoas ao redor a partir de um modelo considerado infalível e inquestionável de bondade e retidão. A liderança servidora tem como objetivo não exaltar somente o líder, dentro do paradigma industrial de liderança e administração, mas também conferir valor aos seguidores/subordinados, pois sem eles o trabalho em equipe não seria executado. Ainda assim, é muito significativo que muitos queiram ser líderes e, não mais, gerentes, diretores - nem muito menos, liderados.

Podemos pensar em futuras pesquisas sobre que tipo de diferença no mundo este modelo visa promover, quando vemos o crescimento de iniciativas de liderança em igrejas evangélicas e em organizações cristãs. Nelas encontramos o incentivo à eficácia, à excelência, ao empreendedorismo, à vitória - nas igrejas, isso se traduz em crescimento numérico, otimização de recursos e visibilidade. Entre os indivíduos, implica a medida do sucesso como felicidade e realização pessoal, respaldados pelo exemplo da figura de Jesus - como se o seu modelo justificasse suas conquistas. É preciso verificar se os livros que têm sido lançados trabalham nesta mesma perspectiva, ou se há espaço para outros valores dentro destes modelos de liderança. Além disso, esse tema abre caminhos para se pesquisar não só modelos de liderança baseados em outras figuras religiosas, como também as relações entre espiritualidade, mídia, trabalho e economia do dinheiro e das emoções. Trata-se, enfim, de um campo ainda em exploração, tanto no presente quanto no passado. 


\section{REFERÊNCIAS BIBLIOGRÁFICAS}

ANKER, R. Self-Help and Popular Religion in Early American Culture: An Interpretive Guide (American Popular Culture) (v. 1). Greenwood, 1999.

BARTON, B. The man nobody knows. Bobbs-Merill Company Inc. - The Grow Foundation. Ebook - public domain, 1925;

BASS, B. M. \& R. The Bass Handbook of Leadership: Theory, Research, and Managerial Applications. Free Press, 1981.

BLANCHARD, K. e HODGES, P. Lidere como Jesus: lições do maior modelo de liderança de todos os tempos. Rio de Janeiro: Sextante, 2007 (2005).

BLANCHARD, K. e JOHNSON, S. O gerente-minuto: como tomar decisões rápidas - guia prático do executivo moderno. Rio de Janeiro: Record, s/data (original de 1981), $11^{\mathrm{a}} \mathrm{ed}$.

BLANCHARD, K. Foreword: The Heart of the Servant-Leadership In: SPEARS, L. C. \& LAWRENCE, M. Focus on the Leadership: Servant-Leadership for the Twentieth Century. New York: John Wiley and Sons., 2002, pp. IX-XII.

BURKE, K. Literature as Equipment for Living. In: RICHTER, David H (ed.). The Critical Tradition-Classic Texts and Contemporary Trends. Boston: Bedford Books, 1998, pp. 593-598 (originalmente publicado em Direction 1 (April 1938, pp. 10-13).

COHEN, C. \& BOYER, P. (orgs.) Religion and the culture of print in Modern America. Madison: The University of Wisconsin Press, 2008.

FEARCH, Shann Ray et allii. (eds.). Conversations on servant-leadership - insights on human courage in life and work. Albany: SUNY (State University of New York) Press, 2015.

FRANK, T. E. The discourse of leadership and the practice of administration. Journal of Religious Leadership. Vol. 1. No. 1. (Spring 2002), pp. 7- 30.

GREENLEAF, R.K. The Servant as Leader. Disponível em: http://www.leadershiparlington.org/pdf/TheServantasLeader.pdf. Acesso em 15 fev. de 2016.

COVEY, S.R. Foreword In: GREENLEAF, Robert K. Servant Leadership (25th anniversary edition) - A Journey into the Nature of Legitimate Power \& Greatness. New Jersey: Paulist Press, 2002, e-book.

HOOVER, S.M. Religion in the media age. New York: Routledge, 2006

HUNTER, J.C. Como se tornar um líder servidor: os princípios de liderança de "O monge e o executivo". Rio de Janeiro: Sextante, 2006, 6ª ed. (2004).

HUNTER, J.C. O monge e o executivo: uma história sobre a essência da liderança. Rio de Janeiro: Sextante, 2004 (1998).

HUNTER, J.C. De volta ao mosteiro. Rio de Janeiro: Sextante, 2014.

JONES, L.B. Jesus CEO - com Jesus no coração da empresa - usando a sabedoria milenar para uma liderança criativa. Rio de Janeiro: Ediouro, 1996 [1995]. 
MILlER, D. W. God at Work: The History and The Promisse of the Faith at Work Movement. New York: Oxford University Press, 2007.

MOTTA, P. R. Apostila MBA - FGV. Módulo Liderança e Inovação. Rio de Janeiro: FGV, 2011.

PROTHERO, S. American Jesus: how the Son of God became a National Icon. Farrar, Straus and Giroux, 2004.

ROST, J. C. Leadership for the Twentieth-first century. Westport/Connecticut/London: Greenwood Publishing Group, 1991.

SMITH, E. A. What would Jesus read? Popular religious books and everyday life in twentiethcentury America. Chapel Hill: The University of North Carolina Press, 2015.

Recebido em: 25/10/2017 Aprovado em: 11/01/2018 